\section{EXPERT, BESPOKE ADVICE}

Made up of dedicated experts, Breathe Business offers outstanding advice, support and guidance to your dental practice. Breathe Business has a unique set of attributes:

- It is not a 'one-man band.' It has an experienced, comprehensive team of experts always on hand to help

- The team has set up, run and sold successful dental practices (and other businesses) and help clients to do the same

- Some of the team are dentists and so understand exactly what it's like!

- Breathe is all about the client

- The team is there every step of the way, helping clients to implement the best strategies for their individual practices

- Breathe Business doesn't do 'one size fits all.' All services are tailored to suit the client's objectives

- The business has built a large community of like-minded principals, dentists and their teams. The growing 'tribe' includes a network of experts and professionals, which the team introduces clients to.

If you need assistance and could use some expert advice, don't hesitate and call Breathe today.

Reader response number 53

\section{CLEVERLY DESIGNED STOOL}

Sitting with the correct posture is very important as it relieves the strain on your lower back. Bambach's unique saddle seat design allows the spine and pelvis to work together to create balance and mobility in the upright position. As a result good posture happens naturally as you sit on this cleverly designed stool which encourages 'dynamic' seating. Due to the unique design of this stool, your feet are free to move to and from your foot pedal without altering your

\section{IMPRESS YOUR PATIENTS}

Although high quality patient care is every dentist's number one priority, your practice is still a business and needs to be run and advertised as such. Creating an impact using the right kind of stationery can make all the difference when it comes to standing out from the competition and impressing patients.

The right stationery can speak volumes about your practice - from what font you choose to the type of paper you print on, it all has an impact.

Finding a good stationery design and printing service can be a daunting prospect, but with over 30 years of experience working with dental practices throughout the UK, Admor is posture further promoting health. This helps not only reproduce the stress free ' $S$ ' shape of the spine but maintain it effortlessly all day long.

Bambach stools are available in a wide variety of colours and finishes to harmonise with the modern dental practice.

So for natural relief and to prevent occupational back pain for all members of the dental team, choose Bambach. There's even a free 30 day trial period. Reader response number 54

well placed to assist when it comes to producing corporate stationery.

Offering a full complement of services, including design, print and distribution, Admor can help your practice to create stylish full colour business cards, reception posters, brochures and marketing leaflets without having to break the bank.

Having invested in the latest print technology, Admor can offer you a bespoke print service of the highest quality, are competitive at any quantity, and can arrange the postal distribution of any finished product making them ideal for marketing campaigns and other communications with your clients.

To see how you can make your practice shine, talk to Admor. Reader response number 55

\section{RETAINING THE VALUE OF YOUR BRAND}

Marketing your dental plans is an important part of running a successful practice. The plan itself must be of financial benefit to patients and patients need to be made aware of the plan and understand how it can help them budget for their oral care needs.

For private practices the strength of the 'brand' is a key investment priority as ultimately it is the brand that retains the inherent value. So anything that can add to your brand value has to be worthwhile and this is where a practice-branded payment plan comes into its own.

DPAS administer practice branded plans on behalf of client practices, providing an efficient, cost effective administration service. But their support goes much deeper, assisting with the practical elements of marketing such as brochure design and distribution, ultimately providing the help you need whilst maintaining a 'backstage' position and allowing you to stay in control.

DPAS provide everything necessary to launch and maintain your plan and the Marketing Toolbox is just one of the exclusive benefits available to DPAS customers. This interactive website helps practice teams to understand and embrace marketing techniques, providing ready-to-use practical tips and tools.

Resources include advice on marketing, PR, advertising and e-commerce, as well as template referral letters and newsletters. The site also features exclusive deals from a variety of providers and discussion boards to encourage practices to interact with each other and share their marketing experiences.

Reader response number 56

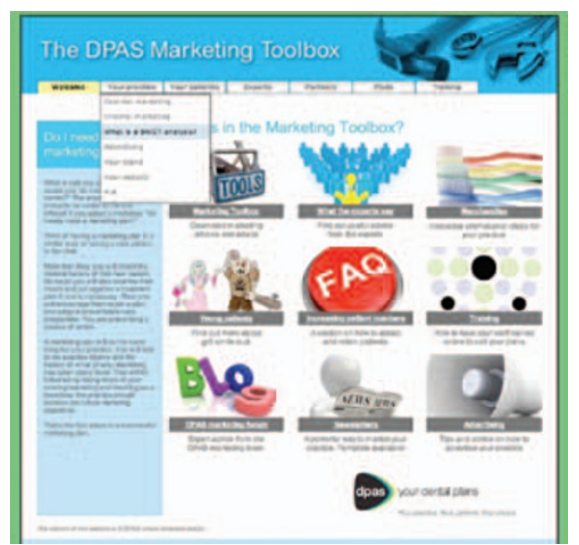

